
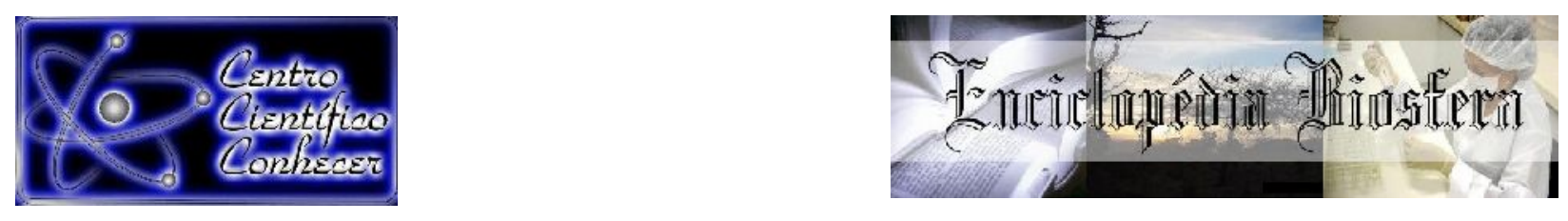

\title{
PREVALÊNCIA DO VÍRUS DA IMUNODEFICIÊNCIA FELINA (FIV) E DO VÍRUS DA LEUCEMIA (FELV) EM UM GATIL, NO MUNICÍPIO DE UBERLÂNCIA - MG - UM ESTUDO DE CASO
}

Camila Silva Carneiro ${ }^{1}$, Eduardo Francisco Ferreira de Andrade ${ }^{1}$, Patrícia Alves Teixeira², Danilo Guedes Junqueira Júnior ${ }^{3}$

1 Bacharel em Medicina Veterinária do Centro Universitário do Triângulo, Uberlândia-MG, Brasil.

${ }_{2}^{2}$ Professora Mestre do curso de Medicina Veterinária do Centro Universitário do Triângulo, Uberlândia-MG, Brasil.

3 Professor Doutor do curso de Medicina Veterinária do Centro Universitário do Triângulo, Uberlândia-MG, Brasil.

Email de contato: dan_hp2002@yahoo.com.br

Recebido em: 15/02/2020 - Aprovado em: 15/03/2020 - Publicado em: 30/03/2020

DOI: 10.18677/EnciBio_2020A18

\begin{abstract}
RESUMO
Investigou-se a prevalência da infecção pelo vírus da Imunodeficiência Felina (FIV) e pelo vírus da Leucemia Felina (FeLV) em gatos domésticos, provenientes do gatil da Associação de Proteção Animal, do município de Uberlândia/MG. Amostras de sangue de 20 animais foram coletadas e testadas para detecção de FIV e FeLV, através de testes sorológicos pelo método ELISA. Observou-se apenas um macho positivo para FIV (Prevalência aparente de 5,0\%, IC: 0,89\% - 23,61\%) e nenhum animal positivo para FeLV. Sendo assim, o gatil se encontra livre de Leucemia Felina, e possui uma prevalência baixa de Imunodeficiência Felina, além disso todos os animais se encontram clinicamente saudáveis, em ótimo estado de nutrição e aptos para adoção.
\end{abstract}

PALAVRAS-CHAVE: Abrigo, Diagnóstico, Retrovírus

\section{PREVALENCE OF FELINE IMMUNODEFICIENCY VIRUS (FIV) AND FELINE LEUKEMIA VIRUS (FELV) IN A CATTERY IN UBERLÂNDIA / MG - A CASE STUDY}

\begin{abstract}
The prevalence of Feline Immunodeficiency virus (FIV) and Feline Leukemia virus (FeLV) infection in domestic cats from cattery Animal Protection Association of the city of Uberlândia/MG was investigated. Blood samples from animals were collected and tested for FIV and FeLV through serological tests by the ELISA method. A male positive for FIV (apparent prevalence rate 5,0\%, IC: 0,89\%-23,61\%) and no FeLV positive animal was observed. Thus, the cattery is free of Feline Leukemia, and has a low prevalence of Feline Immunodeficiency. In addition, all animals are clinically healthy, in good nutrition and fit for adoption.
\end{abstract}

KEYWORDS: Diagnosis, Retrovirus, Shelter 


\section{INTRODUÇÃO}

A população de gatos domésticos, pertencentes à espécie Felis catus, têm crescido consideravelmente no Brasil, e estima-se, segundo o último levantamento realizado pelo Instituto Brasileiro de Geografia e Estatística (IBGE) em 2013, que existem aproximadamente 22,1 milhões desses animais em 11,5 milhões de residências, sendo que as regiões Norte $(22,7 \%)$ e Nordeste $(23,6 \%)$ alcançam os primeiros lugares sobre a quantidade de gatos por residência. $\mathrm{E}$ as regiões Sul $(19 \%)$, Sudeste $(13,5 \%)$ e Centro-Oeste $(14,3 \%)$ com as menores porcentagens (IBGE, 2013).

A Imunodeficiência Viral Felina (FIV) e a Leucemia Viral Felina (FeLV) são doenças infecciosas causadas por um retrovírus que acomete a espécie dos felídeos, tanto os gatos domésticos quanto os selvagens, e tem uma abrangência mundial com prevalências que variam de $4 \%$ a $24 \%$ e de $1 \%$ a $44 \%$, respectivamente, sendo que os animais infectados dificilmente chegam a fase adulta devido ao fato da associação de sobrevivência entre dois e três anos de idade. (TEIXEIRA et al., 2007; CHHETRI, 2015).

FIV e FELV podem ser encontradas nas cinco regiões do Brasil, em clínicas, hospitais, abrigos e residências particulares, com uma prevalência no Brasil de 2 à $37,5 \%$ para FIV e 8 à $63 \%$ para FELV (BARROS et al., 2017). Ambas não apresentam risco aos humanos e suas formas de transmissão são horizontal através do contato com saliva, secreções respiratória e sêmen, e pode ocorrer também de forma vertical através do contato intrauterino e pelo leite materno. De acordo com Hagiwara (2016) a principal forma de contaminação com o vírus da FIV é através da mordida que a saliva é inoculada na corrente sanguínea contaminando o animal com o retrovirus.

Os vírus da FIV e FeLV possuem propriedades que causam imunossupressão, debilitando 0 animal e causando-lhes enfermidades degenerativas e infecções secundárias, como gengivites, conjuntivites, enterites, e desenvolvendo linfomas, leucemias, entre outras (SOBRINHO et al., 2011).

$O$ diagnóstico pode ser feito através de exames clínico e laboratoriais. Através dos testes sorológicos pelo método de Ensaio Imunoenzimático (ELISA) identifica-se anticorpos contra FIV e antígenos de FeLV, e há ainda o uso de testes moleculares como o de Reação em Cadeia da Polimerase (PCR) (TEIXEIRA et al., 2007). Para a detecção dos anticorpos os meios moleculares são mais sensíveis no período de duas a quatro semanas após a infecção, e nos estágios terminais da FIV, consequentemente, a resposta do anticorpo é baixa (WILKES, 2015).

Por se tratar de infecções de fácil transmissão e enfermidades debilitantes com altos níveis de morbidade o estudo das mesmas é de grande importância na clínica médica de pequenos animais, bem como o estudo da soroprevalência em gatis, ambientes domésticos e com animais errantes, possibilitando novos programas de controle e prevenção, com a finalidade de erradicar estas enfermidades e diminuir os impactos negativos e possibilidades de novas transmissões. Além disso, o certificado de que o gatil é livre dessas doenças permitirá o resgate e abrigo de novos animais, como também a adoção dos animais testados.

Objetivou-se avaliar a prevalência dos vírus da FIV e FeLV nos gatis da Associação de Proteção Animal de Uberlândia/MG - APA, com a finalidade de permitir a implementação de medidas preventivas, bem como o tratamento das 
enfermidades e de infecções secundárias que os animais infectados pudessem apresentar.

\section{MATERIAIS E MÉTODOS \\ Local de Estudo e Amostragem}

O estudo foi realizado na Associação de Proteção Animal - APA, localizada em Uberlândia - MG, instituição que resgata e abriga animais em situações de risco e abandonados, promovendo projetos que contribuam com a qualidade de vida deles, oferecendo-Ihes alimentação, atendimentos veterinários, medicações e contribui com as adoções. A associação possui dois gatis que abrigam aproximadamente 25 animais em cada.

A amostra para estudo foi constituída por 20 animais adultos, independente do sexo, escore corporal, estado de imunização e esterilização, optando pelos mais dóceis com objetivo de evitar medidas de contenção. Os animais passaram por avaliações físicas que confirmaram um bom estado de saúde geral, também vale ressaltar que eles não possuíam nenhum histórico de vacinação contra as retroviroses mencionadas, apenas contra o vírus da raiva.

\section{Coleta de sangue e teste sorológico}

Foi coletado em cada animal, cerca de um $\mathrm{mL}$ de sangue, por venopunção da veia cefálica, utilizando seringas de $3 \mathrm{~mL}$ com agulhas de $0,38 \mathrm{~mm}$ de diâmetro e frascos de coleta apropriados contendo anticoagulantes como EDTA. O material foi armazenado sob refrigeração (até $7{ }^{\circ} \mathrm{C}$ ) e foi submetido à uma centrifugação para separação do plasma no laboratório de Análise Clínica do Centro Universitário do Triângulo (UNITRI). Em seguida, foi adicionado ao material coletado juntamente com uma gota de plasma e duas gotas de tampão diluente ao cassete do teste de diagnóstico de imunoensaio cromatográfico rápido, da marca Alere® FIV Ac/FeLV Ag Test Kit (São Paulo, Brasil), a fim de detectar qualitativa e simultaneamente anticorpos IgG do vírus da FIV e antígenos p27 do vírus da FeLV.

\section{Análise Estatística}

A base de dados, assim como a construção de tabelas foi realizada por planilhas eletrônicas do programa Microsoft Excel versão 2013. Na base de dados, cada amostra de soro sanguíneo contém o local, idade do animal, sexo, espécie, e data da coleta.

\section{Prevalência de animais infectados}

A interpretação do teste sorológico se deu em 10 minutos e o animal considerado doente foi aquele que apresentou duas linhas coloridas (C e T) em ambos os cassetes dos testes, indicando o resultado positivo. A prevalência aparente $(\mathrm{Pa})$ e real $(\mathrm{Pr})$ foram calculadas conforme Noordhuizen et al. (1997) e Bennett et al. (1991). Os valores de Pr foram estimados ajustando-se o valor da $\mathrm{Pa}$ para a especificidade (FIV 0,98 / FeLV 1) e sensibilidade (FIV 0,96 / FeLV 1) do teste de ELISA (CUMBERLAND et al., 1999). Foi usada a seguinte fórmula: $\operatorname{Pr}=(\mathrm{Pa}+$ Esp-1) / (Sen + Esp-1), onde: Sen = sensibilidade do teste; $\mathrm{Pa}=$ prevalência aparente; $\mathrm{Esp}=$ especificidade do teste.

Os intervalos de confiança (IC) das prevalências aparente e real de animais foram calculados para uma confiança de 95\%, conforme Martin et al. (1987), através 
da seguinte fórmula: IC = valor estatístico $\pm(z$ * $E P)$, onde: $z=1,96$ (SAMPAIO, 2007); EP = erro- padrão.

O cálculo do Valor Preditivo Positivo (VPP) realizou-se conforme Thrusfield (2005), foram considerados os valores referidos acima para sensibilidade e especificidade e uma prevalência de $24 \%$ para ambas as doenças. O cálculo foi feito a partir da fórmula: VPP $=$ Prevalência $\times$ Sensibilidade $/$ (Prevalência $\times$ Sensibilidade) $+\{(1-$ Prevalência $) \times(1$-Especificidade $)$

\section{RESULTADOS E DISCUSSÃO}

A amostragem de 20 gatos foi composta por 06 fêmeas (30\%) e 14 machos (70\%), todos sem raça definida, adultos, com idade entre um e cinco anos, sadios e sem nenhum sinal clínico condizente com as enfermidades abordadas. Dos 20 animais, somente um (5\%) apresentou anticorpos contra o vírus da FIV, porém não apresentou nenhum sinal clínico referente à enfermidade.

TABELA 1: Prevalência aparente, intervalo de confiança, prevalência real de FIV em felinos de um abrigo coletivo, Uberlândia, MG, 2018.

\begin{tabular}{lll}
\hline $\mathrm{Pa}$ & $\mathrm{IC} 95 \%$ & $\mathrm{Pr}$ \\
\hline $5 \%$ & $0,89-23,61$ & 3,19 \\
\hline
\end{tabular}

Fonte: dados da pesquisa

Com relação à FeLV, todos os animais apresentaram resultado negativo, diferente de um estudo realizado na cidade de Uberlândia-MG, que verificou a prevalência dessa enfermidade com amostragens de animais atendidos no Hospital Veterinário da Universidade Federal de Uberlândia e do Centro de Zoonoses de Uberlândia. E encontraram resultados positivos como $20 \%$ das amostras vindas do Centro de Zoonoses contra 5,71\% das que vieram do Hospital Veterinário. Isso comprova também que os animais que possuem acesso às ruas estão mais propensos à infecção por retrovírus (BARBOSA et al., 2001).

Apesar de outros estudos demonstrarem que as ocorrências de infecções por retroviroses felinas serem influenciadas por fatores como o desconhecimento da procedência desses animais, a alta densidade populacional e íntimo contato entre os mesmos nos locais onde vivem, nesse estudo não foi possível verificar a significância destes fatores, já que os animais testados possuem essas características.

De acordo com estudo sorológico, apenas um dos 20 animais apresentou anticorpos contra o vírus da FIV, porém o mesmo se encontrava clinicamente saudável diferente de estudo publicado por Sobrinho et al. (2011) que verificaram a sorofrequência de FIV e FeLV em gatos no município de Araçatuba-SP e relataram que vários animais infectados pelo FIV apresentaram alterações clínicas como apatia, linfoadenomegalia, perda de peso, desidratação, hepatoesplenomegalia, secreção ocular bilateral purulenta e estomatite, bem como dermatopatias e outras infecções secundárias.

Já no trabalho realizado por Poffo et al. (2017) na cidade de Cuiabá, Mato Grosso em uma pesquisa realizada com 88 gatos, 11 animais foram positivos para FIV, quatro para FELV e dois foram positivos para ambas as patologias. A pesquisa foi feita no Hospital Veterinário Universitário da cidade, em conjunto foi feita uma pesquisa sobre o acesso à rua e não se demonstrou significância estatística. 
Já em um trabalho realizado por Costa et al. (2017) foram testados 493 gatos sendo que destes $153(31 \%)$ foram detectados positivos para FELV, $50(10,1 \%)$ para FIV e $22(4,4 \%)$ com ambas as doenças, com suas pesquisas concluíram que houve significância entre a idade até um ano para resposta de FELV. Observaram ainda uma maior prevalência para FIV em gatos machos, justificada pelo fato de machos serem mais territorialistas e a patologia é transmitida através da mordida, contato com a saliva ou do acasalamento.

Westman et al., (2015) fizeram a comparação do ensaio imunoenzimático e o ensaio imunocromográfico e obtiveram resultados semelhantes e com precisão para detectar a FIV e FELV. A técnica de diagnóstico empregada apresenta, segundo o fabricante, especificidade de 0,98 e sensibilidade de 0,96. O Valor Preditivo Positivo (VPP) indica a probabilidade da presença da doença quando o resultado do teste é positivo. Para o presente estudo, obteve-se previamente um valor de $95,05 \%$ para o VPP para uma prevalência esperada de $50 \%$, entretanto a prevalência encontrada no estudo foi menor do que o valor inicial esperado, o que reduziu o VPP para $61,26 \%$. Deste modo, é possível que o felino identificado como doente para FIV, seja um falso- positivo.

Através deste estudo pode-se concluir que o gatil da APA de Uberlândia-MG, se encontra livre da retrovirose FELV e possui uma baixa prevalência para FIV. Além disso, vale ressaltar que todos os animais se encontram clinicamente saudáveis, em ótimo estado de nutrição e serão submetidos a outros testes sorológicos para que se tornem aptos à adoção, não apresentando nenhum risco infeccioso ao ser humano e nem a outros animais.

\section{REFERÊNCIAS}

BARBOSA, F. C.; CHRISTIANINE, M. P. T.; WALDEMARIN, K. C. A. Prevalência de Leucemia Felina em gatos domésticos de Uberlândia-MG. Arquivo de ciências veterinária e zoologia da UNIPAR, 5 (2): p.207-211, 2001. Disponível: https://revistas.unipar.br/index.php/veterinaria/article/view/771.

DOI: doi.org/10.25110/arqvet.v5i2.2002.771

BARROS V.R., BEZERRA J.A.B., BOCHNAKIAN M.S., PAULA V.V.; FILGUEIRA K.D. 2017. Epidemiology of feline immunodeficiency virus and feline leukemia virus in a veterinary teaching hospital. Revista Brasileira Higiene e Sanidade Animal. 11(2):151-160. Disponível em: <http://dx.doi.org/10.5935/1981-2965.20170016>

BENNET, S.; WOODS, T.; LIYANAGE, WM et al. A simplified general method for cluster-sample surveys of health in developing countries. World Health $\begin{array}{lllll}\text { Statistics Quaterly, } & \text { v.44, n.3, p. } & \text { 98-106, } & 1991 .\end{array}$ Disponível em: https://apps.who.int/iris/handle/10665/47585

CHHETRI BK, BERKE O., PEARL DL E BIENZLE D. 2015. Comparação de fatores de risco para soropositividade ao vírus da imunodeficiência felina e vírus da leucemia felina em gatos: um estudo de caso. BMC Veterinary Research 11: 1-7. Disponível em: https://link.springer.com/article/10.1186/s12917-015-0339-3 DOI: 10.1186/s12917-015-0339-3

COSTA, F. V. A.; VALLE, S. F.; MACHADO, G.; CORBELLINI, L. G.; COELHO, E. $M$. et al. Hematological findings and factors associated with feline leukemia virus 
(FeLV) and feline immunodeficiency virus (FIV) positivity in cats from southern Brazil. Pesquisa veterinária brasileira. 37(12):1531-1536, dezembro 2017. Disponível em: http://www.scielo.br/scielo.php?pid=S0100736X2017001201531\&script=sci_abstract \&tlng=p DOI: $10.1590 / \mathrm{s} 0100-736 \times 2017001200028$.

CUMBERLAND, P.; EVERARD, C.O.R.; LEVETT, P.N. Assessment of the efficacy of an IgM-ELISA and microscopic agglutination test (MAT) in the diagnosis of acute leptospirosis. The American Journal Tropical Medicine. Hygiene. 61(5):731- 734, 1999. Disponível

em: https://www.researchgate.net/publication/12714221_Assessment_of_the_efficacy_of _IgM_ELISA_and_microscopic_agglutination_test_MAT_in_the_diagnosis_of_acute_ leptospirosis DOI: 10.4269 / ajtmh.1999.61.731

IBGE, Instituto Brasileiro de Geografia e Estatística. Pesquisa Nacional de Saúde.2013. Disponível em: https://sidra.ibge.gov.br/tabela/4932

HAGIWARA M.K., RECHE A.J.R. \& TEIXEIRA B.M. 2016. Retroviroses dos felinos: síndrome da imunodeficiência dos felinos, p.836-843. In: Megid J., Ribeiro M.G. \& Paes A.C. (Eds), Doenças Infecciosas em Animais de Produção e de Companhia. Roca, Rio de Janeiro.

MARTIN, SW.; MEEK, AH.; WILLEBERG, P. Veterinary Epidemiology; principles and methods. Ames: lowa State University, 1987. 343p. Disponível: https://vtechworks.lib.vt.edu/handle/10919/72274

NOORDHUIZEN, J.P.T.M.; FRANKENA, K.; VAN DER HOOFD, C.M. et al. Application of quantitative methods in veterinary epidemiology. Wageningen: Wageningen, 1997. $445 \mathrm{p}$

Disponível: https://link.springer.com/article/10.1023/B:TROP.0000009979.16065.5d DOI: doi.org/10.1023/B:TROP.0000009979.16065.5d

POFFO, D. Infecção por vírus da imunodeficiência felina (FIV), vírus da leucemia felina (FeLV) e Leishmania sp. em gatos domésticos no Centro-Oeste do Brasil. Pesquisa veterinária brasileira. vol.37 no.5 Rio de Janeiro maio 2017. Disponível em:

http://www.scielo.br/scielo.php?pid=S0100736X2017000500491\&script=sci_arttext\# B18 DOI: 10.1590/s0100-736×2017000500011

SILVA, A.P.; FLORES, M.; MAZARO, R.; LUZ, F.; SILVA, M. et al. Afecções orais e retroviroses em gatos de abrigo. Pesquisa Veterinária Brasileira. [online]. 2019, vol.39, n.7, pp.516-522. Epub Sep 30, 2019. Disponível em: http://www.scielo.br/scielo.php?pid=S0100736X2019000700516\&script=sci_abstract \&tlng=pt DOI: doi.org/10.1590/1678-5150-pvb-5892.

SOBRINHO, L. S. V.; VIDES, J. P.; BRAGA, E. T.; GOMES, A. A. D.; ROSSI, C. N.; MARCONDES, M. Sorofrequência de infecção pelo vírus da imunodeficiência felina e vírus da leucemia felina em gatos do município de Araçatuba, São Paulo. Braz. J. Vet. Res. Anim. Sci., São Paulo, v. 48, n. 5, p. 378-383, 2011. Disponível em: 
TEIXEIRA, B. M.; RAJÃO, D. S.; HADDAD, J.P.A.; LEITE, R.C.; REIS, J.K.P. Ocorrência do vírus da imunodeficiência felina e do vírus da leucemia felina em gatos domésticos mantidos em abrigos no município de Belo Horizonte. Arquivo Brasileiro de Medicina Veterinária e Zootecnia, v.59, n.4, p.939-942, 2007. Disponível em: http://dx.doi.org/10.1590/S0102-09352007000400019

THRUSFIELD, M.V. Veterinary epidemiology, 3ED. 2005. Blackwell Science Ltd WESTMAN, M. E; MALIK, R; HALL, E; SHEEHY, P. A; NORRIS, J. M. Determining the feline immunodeficiency virus (FIV) status of FIV-vaccinated cats using point-ofcare antibody kits. Comparative Immunology, Microbiology and Infectious Diseases, v.42, p.43-52, $2015 . \quad$ Disponível em: https://www.ncbi.nlm.nih.gov/pubmed/26459979 DOI: 10.1016 / j.cimid.2015.07.004

WILKES, R.P.; KANIA, S. A.; TSAI, Y.L.; LEE, P.Y.; CHANG, H.H.; MA, et al. Detecção rápida e sensível do vírus da imunodeficiência felina usando em ensaios isotérmicos isolados baseados em PCR com detecção por PCR de ponto de necessidade plataforma. Journal Veterinary Diagnstic Investigation. 27 (4): 510515, 2015. Disponível em: http://www.scielo.br/scielo.php?pid=S0100736X2017000500491\&script=sci_arttext\#B18 DOI: 10.1177/1040638715593597 